\title{
2.6 Validation of the Measurement of Aortic Stiffness by the CARDIS Laser Doppler Vibrometer
}

\author{
Louise Marais ${ }^{1, *}$, Hakim Khettab ${ }^{1}$, Yanlu Li ${ }^{2}$, Patrick Segers ${ }^{3}$, Roel Baets ${ }^{2}$, Koen Reesink ${ }^{4}$, Soren Aasmul ${ }^{5}$, \\ Mirko De Melis ${ }^{5}$, Pierre Boutouyrie ${ }^{1}$
}

${ }^{1}$ Inserm U970 - PARCC, Paris, France

${ }^{2}$ Ghent University, Ghent, Belgium

${ }^{3}$ bioMMeda - Institute Biomedical Technology, Ghent University, Ghent, Belgium

${ }^{4}$ CARIM, Maastricht University Medical Center, Maastricht, The Netherlands

${ }^{5}$ Medtronic Bakken Research Center, Maastricht, The Netherlands

\section{ABSTRACT}

Purpose: There is a need for new tools to screen large populations for cardiovascular disease risk. The CARDIS consortium (European Union H2020 funding) developed an easy-to-use, non-contact device for measuring carotid to femoral pulse wave velocity (cfPWV). It consists in a laser doppler vibrometer (LDV), which measures skin vibrations induced by large artery pulses. Pulse waveforms can be tracked and transit time (TT) can be calculated. This study aimed at comparing LDV-cfPWV with the reference cfPWV measured by applanation tonometry (Sphygmocor).

Methods: We included 100 patients with mild to stage 3 hypertension, controlled or not. Reflective tapes were applied on the carotid and femoral arteries to measure LDV-cfPWV 4 times. TT was measured by the foot-to-foot method from the maximum of 2nd derivative using in-house algorithms not requiring ECG, and compared to Sphygmocor (3 acquisitions).

Results: LDV-cfPWV was obtained in $100 \%$ of patients. Mean age was $47 \pm 19$ (range 19-85). Hypertensives were well controlled (119/65 mmHg). Mean value of LDV-cfPWV was $6.9 \pm 1.7 \mathrm{~m} / \mathrm{s}$, compared to $7.5 \pm 1.7 \mathrm{~m} / \mathrm{s}$ with Sphygmocor, bias $0.65 \pm 1.27, \mathrm{R}$ value 0.72 (Figure 1), which qualifies agreement as acceptable according to the guidelines from the ARTERY Society [1]. Reproducibility was good with a median coefficient of variation of 5.6\%. LDV-cfPWV showed similar associations with age and blood pressure than tonometry $(r=0.68, p<0.001$ and $r=0.44, p<0.001$, respectively).

Conclusion: Non-contact measurement of pulse wave velocity by laser doppler vibrometry is feasible, fast and easy to perform, and provides acceptable agreement with reference technique.

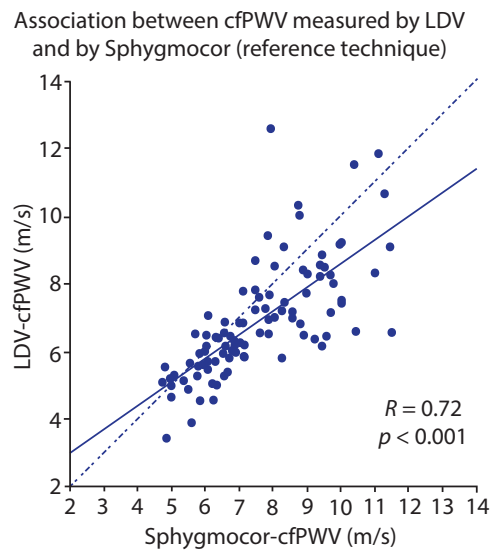

Figure 1

\section{REFERENCE}

[1] Wilkinson IB, McEniery CM, Schillaci G, Boutouyrie P, Segers P, Donald A, et al. ARTERY Society guidelines for validation of non-invasive haemodynamic measurement devices: Part 1, arterial pulse wave velocity. Artery Res 2010;4:34-40.

(C) 2019 Association for Research into Arterial Structure and Physiology. Publishing services by Atlantis Press International B.V. This is an open access article distributed under the CC BY-NC 4.0 license (http://creativecommons.org/licenses/by-nc/4.0/) 